\title{
Analysis of Local Vibrations in the Stay Cables of an Existing Cable-stayed Bridge under Wind Gusts
}

\author{
by \\ Qingxiong WU*, Kazuo TAKAHASHI** and Shozo NAKAMURA**
}

This paper examines local vibrations in the stay cables of a cable-stayed bridge subjected to wind gusts. The wind loads, including the self-excited load and the buffeting load, are converted into time-domain values using the rational function approximation and the multidimensional autoregressive process, respectively. The global motion of the girder, which is generated by the wind gusts, is analyzed using the modal analysis method. The local vibration of stay cables is calculated using a model in which an inclined cable is subjected to time-varying displacement at one support under global vibration. This model can consider both forced vibration and parametric vibration. The response characteristics of the local vibrations in the stay cables under wind gusts are described using an existing cable-stayed bridge. The results of numerical analysis show a significant difference between the combined parametric and forced vibrations and the forced vibration.

Key words: cable, nonlinear vibration, cable-staged bridge, wind gust

\section{Introduction}

Stay cables (hereinafter abbreviated to 'cables') are important components of cable-stayed bridges. Due to their large flexibility, relatively small mass, and very small structural damping, they often exhibit large-amplitude vibrations. The local dynamic behavior of the cables of a cable-stayed bridge under dynamic excitation, such as from winds or earthquakes, can easily be compared to that of a harp whose strings have been plucked. Forced vibrations of this kind have been thoroughly analyzed [1].

Another type of excitation was recognized in the 1980' $\mathrm{s}$. It corresponds to the combined forced and parametric vibrations of cables of cable-stayed bridges due to bending vibrations of the girder and/or towers. The coupling between the deflections of the tower and girder and those of the cables at the supports is responsible for the parametric vibration, i.e., the local parametric vibration of cables excited by girder and/or tower oscillations. This is believed to result in some reported oscillations that cannot be reasonably explained by other phenomena [2].

Generally, if a cable is subjected to axial time-varying displacement at a support due to the global motion of the girder and/or towers, the tension force within the cable changes. When the natural frequency of the global modes in a cable-stayed bridge is close to twice or same as that of the cable, the varying tension force of cables can induce lager-amplitude vibration in the cables. Since multi-cable systems are widely used in cable-stayed bridges, the natural frequencies of the global modes easily become close to the natural frequencies of the stay cables. During vibration tests on the Hitsuishijima cable-stayed bridge, the Yohkura Bridge, and the Tatara Bridge, the local parametric vibrations in some stay cables under excitations in the first some global mode are observed [3].

Analyses have been recently carried out in various fields. These studies established the instability criteria for the fundamental instability regions. In the studies, the cables were given periodic time-varying displacements. However, the studies did not explain the local vibrations in stay cables of cable-stayed bridges under environmental and service loadings, e.g., wind, earthquakes, and traffic loading, which contain a broad spectrum of excitation frequencies. In Ref. [4], the analysis of local vibrations in cables takes into consideration the vibration characteristics of an existing steel cable-stayed bridge under sinusoidal excitations by a moving vehicle or an earthquake.

The other form of excitation related to cable-stayed bridges is wind loading. Stability in wind is an important

Received on June 24, 2005

* Fuzhou University

** Department of Civil Engineering 
consideration in the design of cable-stayed bridges, so the parametric vibration of cables under wind loading should be also examined.

In this study, the local vibrations in the cables of an existing cable-stayed bridge under wind gusts are analyzed. A two-step approach is used to study the local vibrations of the stay cables [4]. The global gust vibration of the bridge is investigated first, followed by an examination of the local vibration of the cables. The local vibration of the cable is obtained using a cable that is fixed at one end and has relative time-varying displacements at the other end. The time-varying displacements at the cable supports are obtained from the global vibration.

The properties of local vibration in cables subjected to wind gusts are derived by means of numerical analysis of an existing steel cable-stayed bridge.

\section{Global Vibration Analysis Due to Wind Gust}

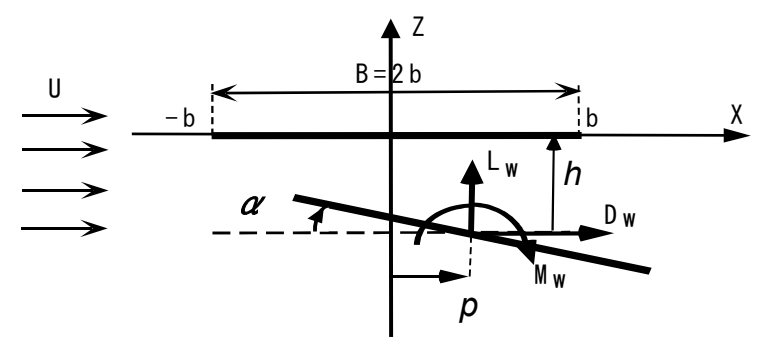

Figure 1 Wind force and displacement components at a point along bridge axis

The global response of a bridge in wind gusts is analyzed by defining the coordinate system and aerodynamic forces as shown in Figure 1. The wind blows lateral to the girder of the bridge and the aerodynamic forces are defined as lift $L_{\|}$ drag $D_{\| k}$ and moment $M_{k^{*}}$ Vibration of girder consists of vertical displacement $h$, horizontal displacement $p$, and torsional displacement $\alpha$.

\section{1 Buffeting Loads}

The buffeting loads per unit span can be expressed based on quasi-steady theory [5]. Fluctuating part $u(x, t)$ along the wind direction and fluctuating part $w(x, t)$ in the vertical direction are calculated through simulations using the autoregression (AR) model. The calculations are done in such a manner that the target power spectrum and coherence to the fluctuating wind velocity are satisfied [6].

\section{2 Self-Excited Loads}

The linearized forms of the self-excited force for sinusoidal deflection components $h(x, t), p(x, t)$, and $\alpha(x, t)$ are obtained from Refs. [5]. The self-excited load is dependent not only on wind speed but also on frequency. In order to transform those frequency-dependent loads into frequency-independent loads, Roger proposed a modal method that employs the rational functions of the Laplace variable and introduces 'lag' coefficients that make the resulting frequency-dependent self-excited aerodynamic forces independent of the frequencies. The application of rational function approximation for flutter and gust analysis of bridges has been the subject of previous studies [5]. In this paper, the linear and nonlinear multilevel optimizations in the least-squares rational function approximation formula are used.

\section{3 Gust Response}

The modal analysis approach is used to compute the state space equation of the extension system expressing the gust response. Subsequently, the global response of the girder under wind gust is obtained by solving equation of motions using the Runge-Kutta method.

\section{Local Vibration Analysis of Cables Consider ing Parametr ic Vibration}

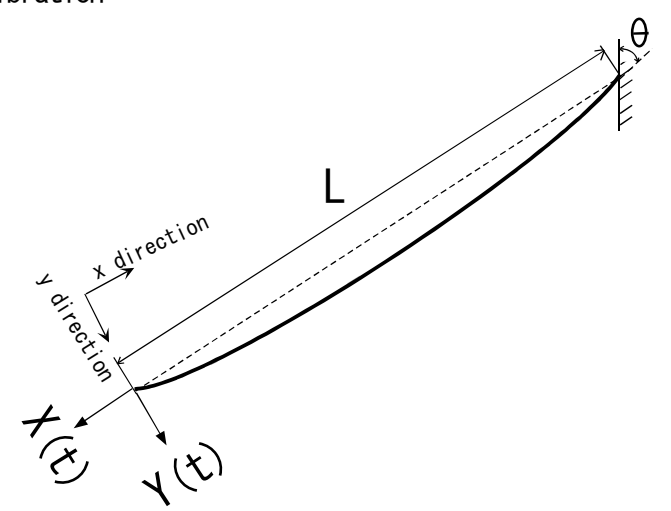

Figure 2Stay cable and its boundary conditions

A model of an inclined cable on a cable-stayed bridge is shown in Figure 2. The cable in this model is fixed at one end and has time-varying displacements $(X(t), Y(t))$ at the other end. Displacement components $X(t)$ and $Y(t)$ are relative displacements since the bridge deck and the tower vibrate simultaneously under wind loads. In the present study, the following are assumed for the local vibration analysis of the cables.

(1) The first modes of the cables are considered in the 
analysis.

(2) Effect of dampers installed on cables is omitted.

(3) The quasi-steady theory is used to deal with the aerodynamic damping of the cables subjected to wind. The gust response of the cables for both the global buffeting vibrations of the whole bridge and the local vibrations of the stay cables is neglected.

(4) Lateral (out-of-plane and coupled in-plane and out-of-plane) vibrations are not considered.

The equation of motion for a flat-sag cable is given below [4].

$$
\begin{aligned}
& m \frac{\partial^{2} v_{c}}{\partial t^{2}}-P \frac{\partial^{2} v_{c}}{\partial^{2} x}-\Delta P\left(\frac{\partial^{2} v_{c}}{\partial^{2} x}+\frac{\partial^{2} v_{0}}{\partial^{2} x}\right)=0 \\
& \Delta P=\frac{E A_{C}}{L}\left\{\left.u_{c}\right|_{x=L}-\left.u_{c}\right|_{x=0}+\frac{1}{2} \int_{0}^{L}\left(\frac{\partial v_{c}}{\partial x}\right)^{2} d x+\int_{0}^{L} \frac{\partial v_{c}}{\partial x} \cdot \frac{\partial v_{0}}{\partial x} d x\right\}
\end{aligned}
$$

where $u_{C}$ and $v_{C}$ are the displacements in the axial direction ( $x$ direction) and in the normal direction ( $y$ direction) of the cable (see Figure 2), $m$ is the mass per unit length of the cable, $P$ is the initial tension of the cable, $\Delta P$ is the additional tension produced by local vibration in the cable, $v_{0}=\frac{m g}{2 P}\left(-x^{2}+L x\right)$ is the initial shape of the cable, $E$ is the Young' s modulus of the cable, $A_{c}$ is the cross sectional area of the cable, $L$ is the span of the cable, $g$ is the gravitational acceleration and $t$ is the time.

The following equation describes the assumed responses $u_{c}(x, t)$ and $v_{c}(x, t)$ of the cable, which at one support receives displacement component $X(t)$ in the $x$ direction and displacement component $Y(t)$ in the $y$ direction.

$u_{c}(x, t)=\left(1-\frac{x}{L}\right) X(t)$,

$v_{c}(x, t)=\left(1-\frac{x}{L}\right) Y(t)+\sum_{i=1}^{\infty} T_{i}(t) \sin \frac{i \pi}{L} x$,

where $T_{i}(t)$ is the time function of the $i$-th mode of the cable.

Inserting equation (2) into equation (1) yields a nonlinear equation of motion of the cable. Applying a Galerkin method produces the following nonlinear equation of motion, which considers both structural damping and aerodynamic damping.

$$
\begin{aligned}
& \ddot{T}_{1}(t)+\left(2 \omega_{1} h_{c}+\frac{\rho U A_{c}}{2 m} C_{D}^{C}\right) \dot{T}_{1}(t)+\omega_{1}^{2} T_{1}(t) \\
& +B_{1}(t) T_{1}(t)+B_{2} T_{1}^{2}+B_{3} T_{1}^{3}=B_{4}(t) \\
& \text { where } \quad B_{1}(t)=\omega_{0}^{2}\left(\frac{X(t)}{X_{0}}+\frac{1}{2 L} \cdot \frac{Y^{2}(t)}{X_{0}}-\frac{L A_{1}}{2} \cdot \frac{Y(t)}{X_{0}}\right) \\
& B_{2}=-\omega_{0}^{2} \frac{3 L A_{1}}{\pi} \cdot \frac{1}{X_{0}}, \quad B_{3}=\omega_{0}{ }^{2} \frac{\pi^{2}}{4 L} \cdot \frac{1}{X_{0}},
\end{aligned}
$$

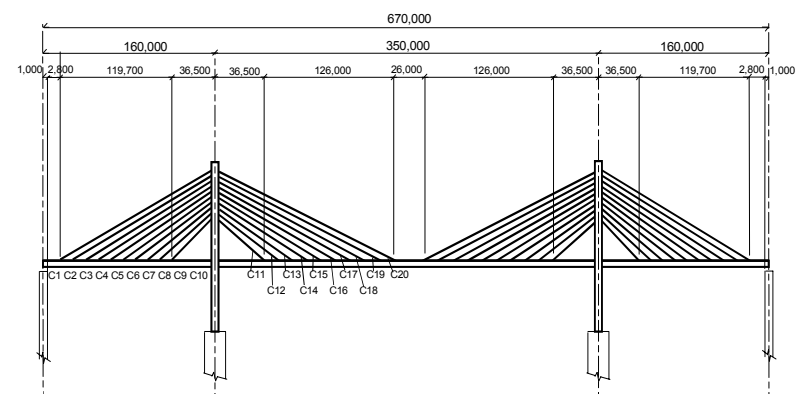

(a) General view

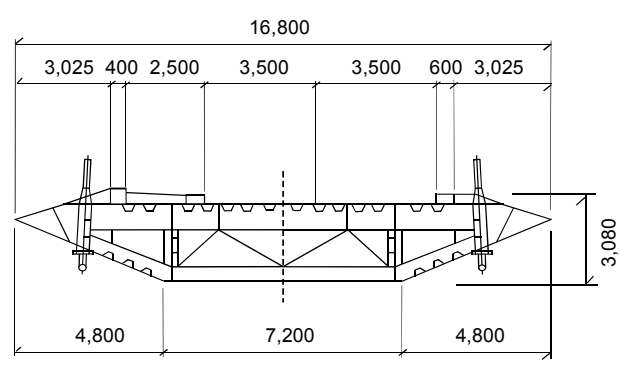

(b) Girder

Figure 3 General view of cable-stayed bridge (unit: $\mathrm{mm}$ )

$$
B_{4}(t)=\omega_{0}^{2}\left\{\begin{array}{l}
-\frac{2}{\pi \omega_{0}^{2}} \cdot \ddot{Y}(t)+\frac{2}{\pi \omega_{0}^{2}} \cdot \frac{\rho U A_{c}}{2 m} C_{D}^{C} \dot{Y}(t) \\
+\frac{4 L^{2} A_{1}}{\pi^{3}} \cdot \frac{X(t)}{X_{0}}+\frac{2 L A_{1}}{\pi^{3}} \cdot \frac{Y^{2}(t)}{X_{0}}-\frac{2 L^{3} A_{1}^{2}}{\pi^{3}} \cdot \frac{Y(t)}{X_{0}}
\end{array}\right\}
$$

, $X_{0}=\frac{P L}{E A}, A_{1}=\frac{m g \sin \theta}{P}, \omega_{0}=\frac{\pi}{L} \sqrt{\frac{P}{m}}$ is the natural circular frequency of the string with no sag, $\omega_{1}=\frac{\pi}{L} \sqrt{\frac{P}{m}} \cdot\left(1+\frac{8 L^{3} A_{1}^{2}}{\pi^{4}} \cdot \frac{1}{X_{0}}\right)$ is the natural circular frequency of the cable considering sag, $h_{c}$ is the damping constant, $\theta$ is the inclined angle, and $C_{D}^{C}$ is the coefficient of drag force.

The response of the cable is obtained by numerical integration of equation (3) using the Runge-Kutta method.

\section{Global Gust Response of Studied Bridge}

0shima Bridge is a steel cable-stayed bridge in Nagasaki, Japan. The main span of this bridge is $350.0 \mathrm{~m}$ and the side spans are $160.0 \mathrm{~m}$. The towers are A-shaped, and the cables are a two-plane, multiple system $[4,7]$. The girder in the three dimensional FE model is a single central spine with offset links to the cable anchor points. The towers and piers are modeled using three-dimensional linear beam elements based on the cross-section properties of actual towers and piers. The cables are modeled as linear truss elements with initial tension. The nonlinear behavior of the cables due to their sags is taken into account by using an equivalent modulus of 


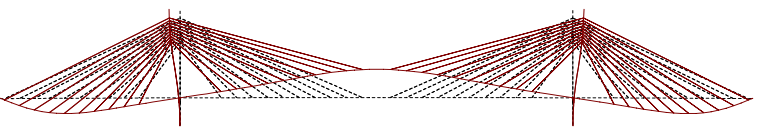

(a) 1st vertical mode $(0.310 \mathrm{~Hz})$

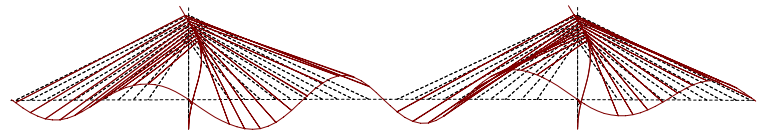

(b) 6th vertical mode $(1.124 \mathrm{~Hz})$

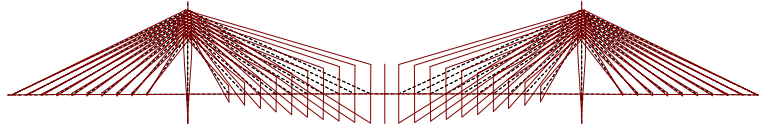

(c) 1st torsional mode $(1.192 \mathrm{~Hz})$

Figure 4Modal shapes of the global vibration

Table 1 Aerodynamic coefficients $(\alpha=0)$

$$
\begin{aligned}
& C_{D}=0.85, \quad C_{L}=0.19, \quad C_{M}=0.01 \\
& C_{D}^{\prime}=0.00, \quad C_{L}^{\prime}=3.42, \quad C_{M}^{\prime}=1.00
\end{aligned}
$$

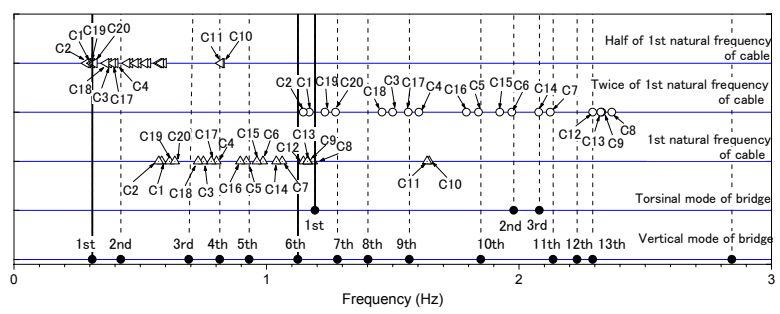

Figure 5 Relationship between natural frequencies of global modes and natural frequencies of cables

elasticity. Regarding the boundary conditions, the girder is free to move in the longitudinal direction and restrained at the supports in the vertical and transverse directions. Only the rotational component around the longitudinal axis is restrained. The tower bases are restrained in all degrees of freedom. The logarithmic decrement of modal damping of the bridge is 0.02 and the time interval of numerical integration is $0.05 \mathrm{~s}$.

Some of the main natural modes obtained from the analysis are shown in Figure 4.

The global vibration analysis in this study takes into account the aerodynamic forces of the girder. The static drag, lift, and moment coefficients of a typical deck on this bridge are listed in Table 1. Although it was originally desirable to obtain the self-excited coefficients $H_{j}{ }^{*}$ and $A_{j}{ }^{*}$ through testing, the present study employs the aerofoil case coefficients. The self-excited coefficients, $P_{j}{ }^{*}$, which concern the horizontal vibration, are evaluated using quasi-steady theory, and the aerodynamic lift and the pitting moment with the horizontal vibration are neglected. The turbulence spectra are defined as the von Karman spectrum [7]. The atmospheric coherence is set using the exponential estimation by Davenport [7].

Using the AR model to simulate a fluctuating wind, the frequency domain of the power spectrum being considered ranges from $0.05 \mathrm{~Hz}$ to $5.0 \mathrm{~Hz}$. The total time is $1200 \mathrm{~s}$ with a time interval of $0.1 \mathrm{~s}$.

\section{Local Vibration Character istics of Cables Under Turbulent Wind}

The local cable vibration is analyzed using the calculated responses of the girder and towers. The responses of the girder at the fixed point for the left cable are not the same as those at the fixed point for the right cable, since the torsional and vertical gust responses are included in the response analysis of the girder. Therefore, 20 cables on each side of the girder are analyzed. The cables are numbered sequentially from the side span to the main span. The cables on the left side are labeled $\mathrm{Cl}^{\sim} \mathrm{C} 20$, and the cables on the right side are labeled $\mathrm{C} 21^{\sim} \mathrm{C} 40$. Since the bridge is symmetric, the cables on the left side (see Figure 3) are used for the numerical calculations.

\section{1 Global Modes and Local Modes}

Figure 5 demonstrates the relationship between the natural frequencies of the global modes and the cables. This figure shows the first natural frequencies of the cables (corresponding to the second unstable region), the natural frequencies multiplied by 2 (corresponding to the principal unstable region), and the natural frequency divided by 2 (corresponding to the second super-harmonic resonance region).

Since the natural frequency of the 3rd vertical mode of vibration is close to the first natural frequencies of cables C18 (C38) (values in parenthesis are for the cable on the right side), the local parametric vibration in the second unstable region in these cables may occur.

\section{2 Local Cable Characteristics}

Figure 6 shows the maximum responses of all cables and the girder at the fixed points of the cables under a wind with a velocity of $L \equiv 30 \mathrm{~m} / \mathrm{s}$. The damping constants $h_{c}$ of the cables are assumed to be 0.001 .

The maximum responses of cables C12 (C32) and C19 (C39) are seen to be greater than those of the other cables. Figure 6 (c) shows that the ratio of the maximum response of cable $\mathrm{C} 32$ 


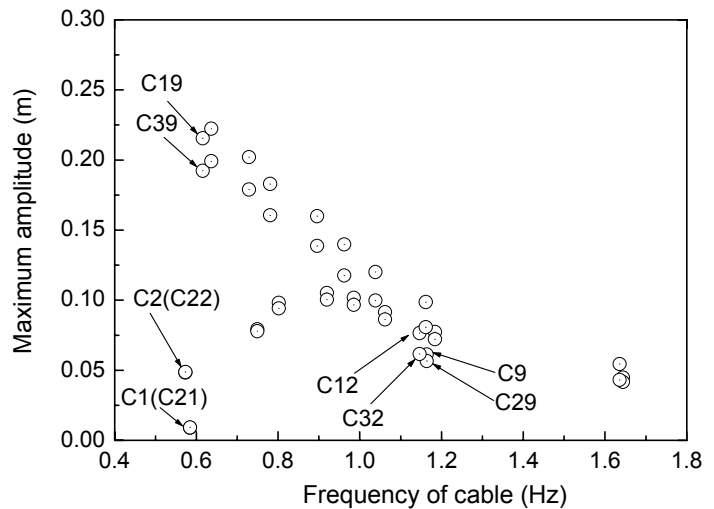

(a) Girder at cable support points

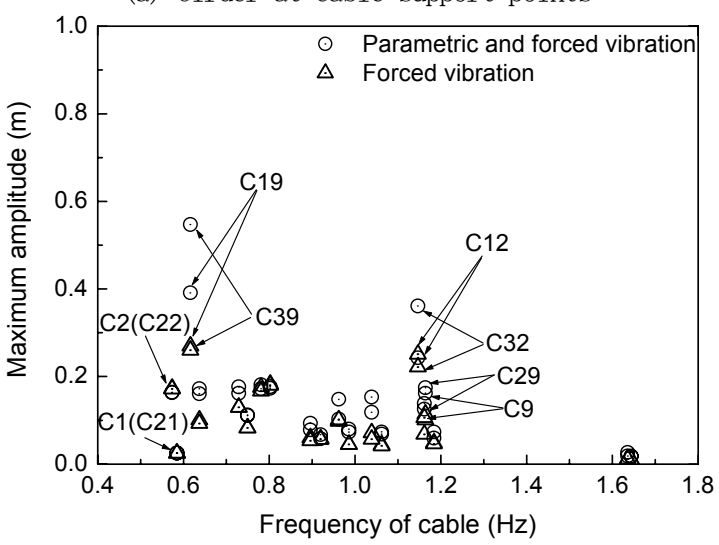

(b) Cables

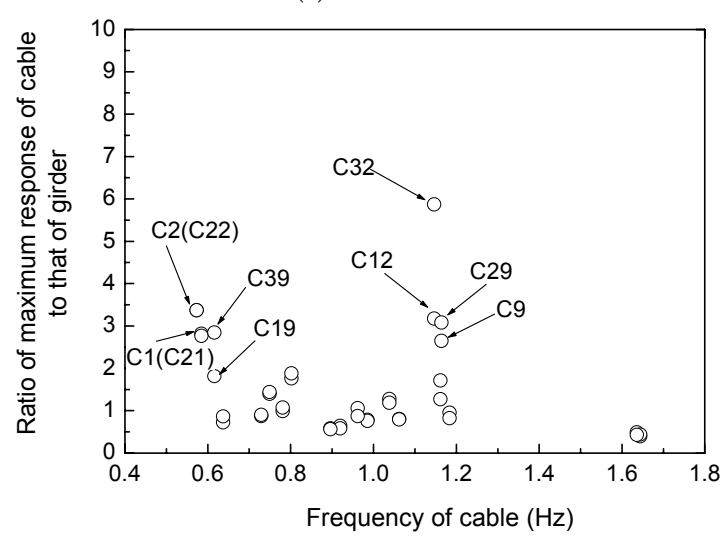

(c) Ratios of Maximum response of cables and girder

Figure 6 Maximum responses of the girder and the cables $\left(\iota \neq 30 \mathrm{~m} / \mathrm{s}, \quad h_{c}=0.001\right)$

to that of the girder is around 6 .

Since the torsional and vertical gust responses at the fixed points of the cables are included (refer to equation (14)), the responses of cables C12 and C32, and cables C19 and C39 differ, even though they have the same natural frequencies.

5. 2. 1 Parametric and/or forced vibrations in Cables $\mathrm{C} 12$ and C32

The response properties of Cables C12 and C32 are discussed

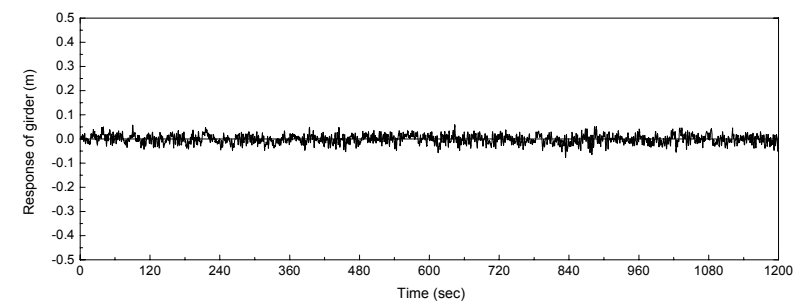

(a) Girder response

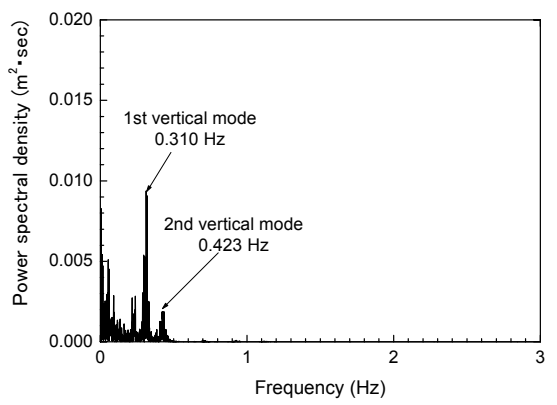

(b) Spectral density of girder response

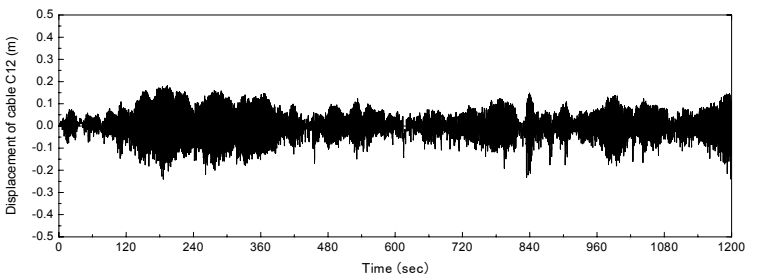

(c) Cable $\mathrm{C} 12$ response

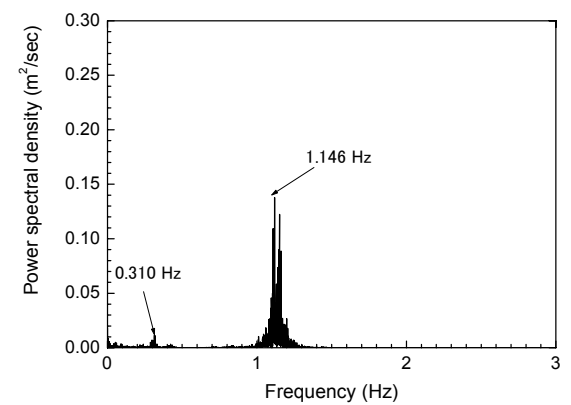

(d) Spectral density of cable $\mathrm{C} 12$ response

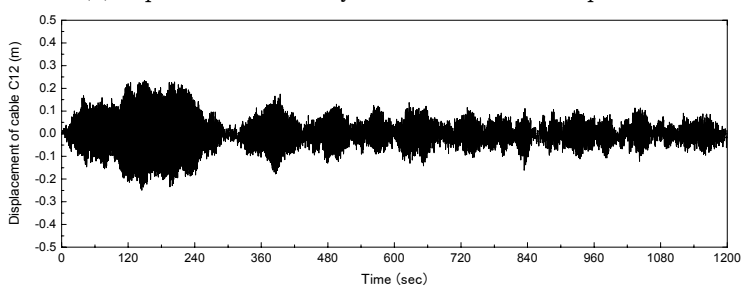

(e) Cable response under forced vibration

Figure 7 Response of the girder and cable $\mathrm{C} 12$ $\left(L \equiv 30 \mathrm{~m} / \mathrm{s}, \quad h_{c}=0.001\right)$

first. The time responses and spectra of the girder and cables C12 are shown in Figure 7.

The predominant frequencies of the girder response are about $0.310 \mathrm{~Hz}$ and $0.423 \mathrm{~Hz}$, while those of cable $\mathrm{C} 12$ are $0.310 \mathrm{~Hz}$ and 1. $146 \mathrm{~Hz}$. It is necessary to examine the reason why the 


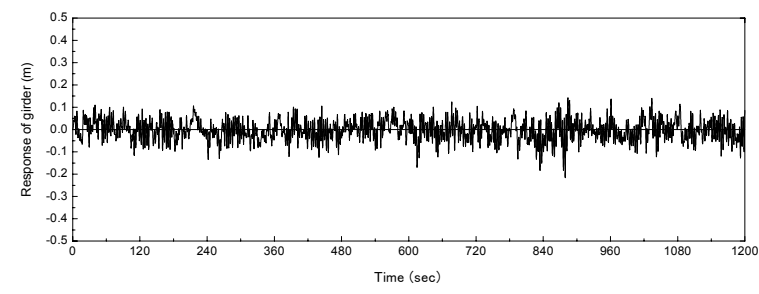

(a) Girder response

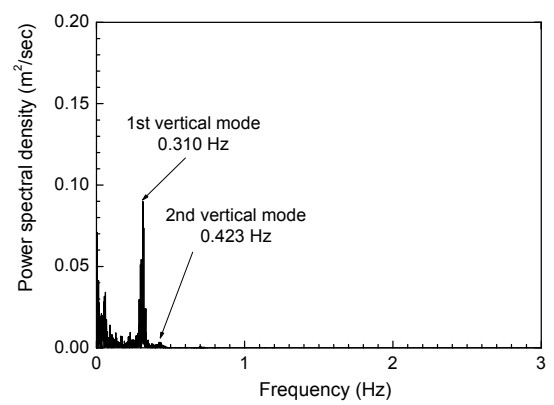

(b) Spectral density of girder response

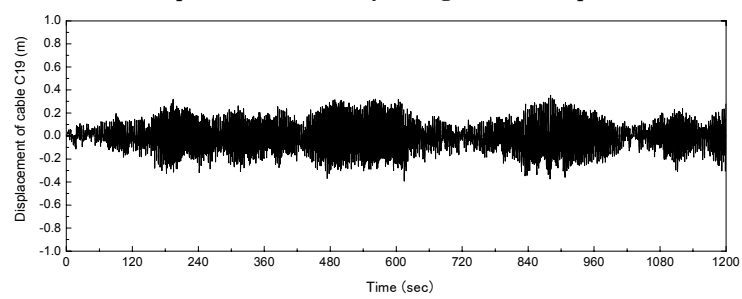

(c) Cable C19 response

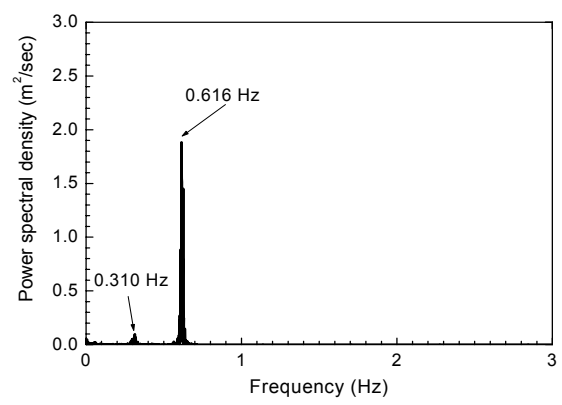

(d) Spectral density of cable $\mathrm{C} 19$ response

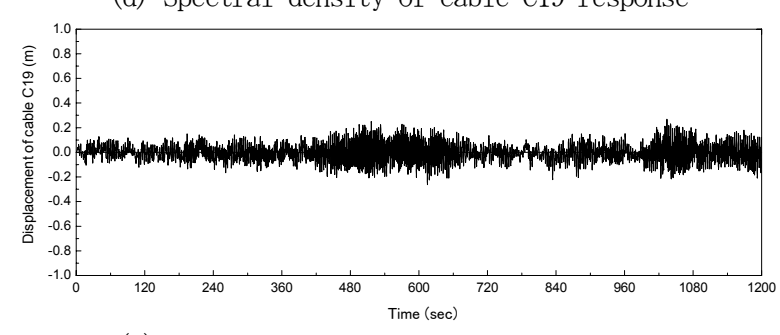

(e) Cable response under forced vibration

Figure 8 Response of the girder and cable C19 $\left(\mathrm{U}=30 \mathrm{~m} / \mathrm{s}, \quad h_{c}=0.001\right)$

vibrations of cables $\mathrm{C} 12$ and C32 become great even when the 6 th vertical mode $(1.124 \mathrm{~Hz})$ is not predominant.

The response of the cable may include components of the parametric vibrations and nonlinear forced vibration with harmonic resonance, super-harmonic resonance or

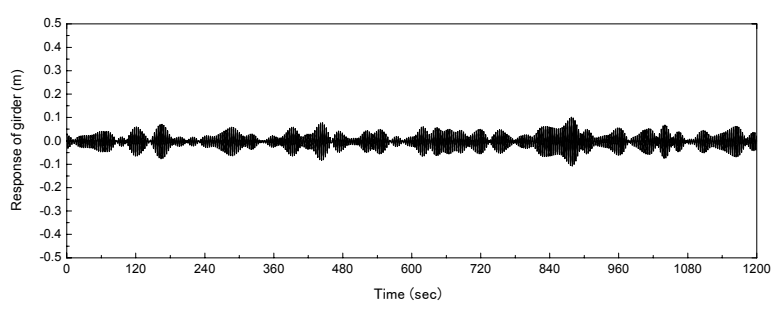

(a) Girder response in $0.280 \sim 0.340 \mathrm{~Hz}$ region

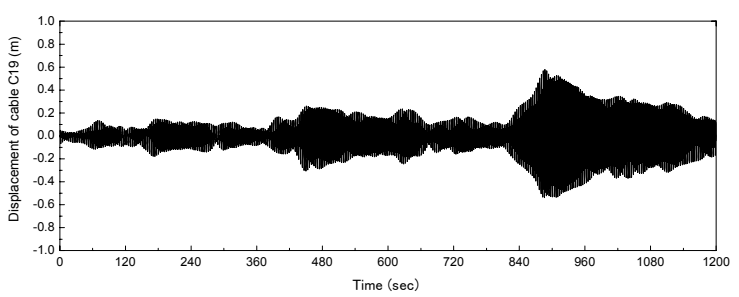

(b) Cable response in $0.280 \sim 0.340 \mathrm{~Hz}$ region

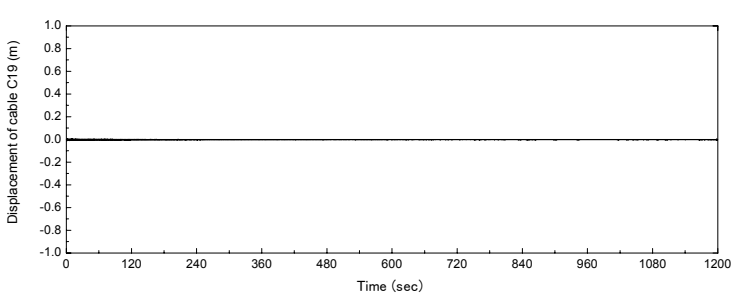

(c) Cable response in $1.024 \sim 1.224 \mathrm{~Hz}$ region

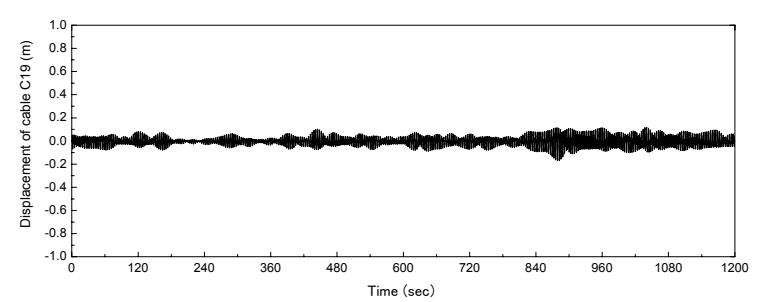

(d) Cable response in $0.280 \sim 0.340 \mathrm{~Hz}$ region under forced vibration

Figure 9 Response of the girder and cable C19 using filter $\left(\mathrm{U}=30 \mathrm{~m} / \mathrm{s}, \quad h_{c}=0.001\right)$

sub-harmonic resonance. These are attributed to the nonlinear equation of motion for the cable, i. e. equation (10). In other words, the properties of a cable cannot be distinguished because the response of the cable includes components of both parametric vibration and forced vibration. Therefore, in order to determine the response characteristics of cables $\mathrm{C} 12$ and C32, it is essential to distinguish the component of parametric vibration from that of forced vibration.

This problem is solved by analyzing the response of the cable and neglecting the component of parametric vibration $B_{1}(t)$ in equation (10). The maximum responses of cables C12 and C32 under forced vibration are listed in Table 3. 
Table 3 Maximum responses of cables C12 and C32

\begin{tabular}{l|l|l|l}
\hline \multirow{2}{*}{ Cable } & \multirow{2}{*}{$\begin{array}{l}\text { Girder amplitude } \\
\text { (m) }\end{array}$} & \multicolumn{2}{|c}{ Cable amplitude (m) } \\
\cline { 3 - 4 } & $\begin{array}{l}\text { Parametric and } \\
\text { forced vibration }\end{array}$ & $\begin{array}{l}\text { Forced } \\
\text { vibration }\end{array}$ \\
\hline C12 & 0.0766 & 0.2427 & 0.2512 \\
\hline C32 & 0.0615 & 0.3613 & 0.2219 \\
\hline
\end{tabular}

Table 4 Maximum responses of cables C19 and C39

\begin{tabular}{l|l|l|l}
\hline \multirow{2}{*}{ Cable } & \multirow{2}{*}{$\begin{array}{l}\text { Girder amplitude } \\
\text { (m) }\end{array}$} & \multicolumn{2}{|c}{ Cable amplitude (m) } \\
\cline { 3 - 4 } & $\begin{array}{l}\text { Parametric and } \\
\text { forced vibration }\end{array}$ & $\begin{array}{l}\text { Forced } \\
\text { vibration }\end{array}$ \\
\hline C19 & 0.2155 & 0.3913 & 0.2698 \\
\hline C39 & 0.1922 & 0.5469 & 0.2600 \\
\hline
\end{tabular}

Since the maximum amplitude of cable $\mathrm{C} 12$ under forced vibration is close to that of the cable under the combined effect of parametric and forced vibrations, it can be concluded that the influence of parametric vibration in $\mathrm{C} 12$ is small while that of forced vibration is great.

Parametric vibration in the secondary unstable region in cable C32 occurs because the maximum amplitude under parametric and forced vibrations is almost twice greater than the maximum amplitude under forced vibration.

\section{2. 2 Second super-harmonic resonance in cables C19 and C39}

The characteristics of cables C19 and C39 are discussed herein. As shown in Table 4, the vibration in cables C19 and C39 is generated under the combined effect of parametric and forced vibrations. This is because the maximum responses under combined parametric and forced vibrations are twice those of the maximum responses under forced vibration. The vibration may be either the parametric vibration in the principle unstable region or the second super-harmonic resonance. From the spectra of the girder and cable C19, shown in Figure 8, the most predominant frequency of response of the girder is about $0.310 \mathrm{~Hz}$, while that of cable $\mathrm{C} 12$ is close to $0.616 \mathrm{~Hz}$. It may be concluded that the second super-harmonic resonance occurs in cable C19 because the ratio of the dominant frequency of the girder to that of $\mathrm{C} 12$ is approximately 0.5 . In order to explore this aspect, a numerical filter based upon Fourier transformation is used to keep the component of the response within the predicted frequency domain and to remove those outside the predicted frequency domain. As can be seen in Figure 5, the frequency at which second super-harmonic resonance may be generated in

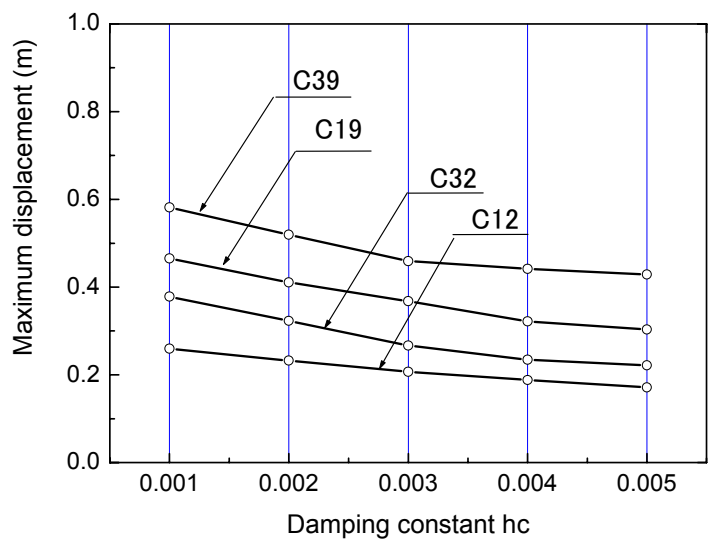

Figure 10Effect of damping on responses of cables

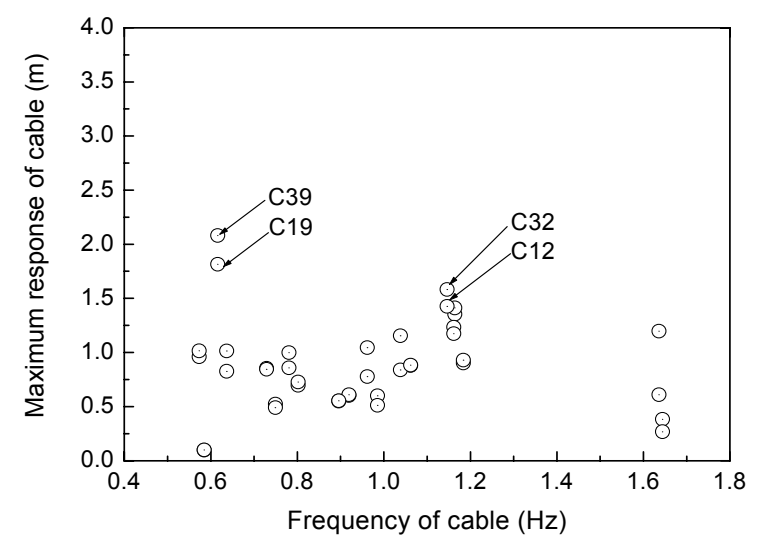

Figure 11 Maximum responses of the girder and the cables $\left(\iota=52 \mathrm{~m} / \mathrm{s}, \quad h_{c}=0.001\right)$

cable $\mathrm{C} 19$ is about $0.310 \mathrm{~Hz}$, and the frequency in which parametric vibration in the principal unstable region may be generated is $1.124 \mathrm{~Hz}$. Therefore, the evaluated region is about $10 \%$ smaller than the original region and is behind those frequencies. In other words, the evaluated region of the response of the girder is within $0.310(1 \pm 10 \%)$ Hz $\approx 0.280 \sim$ $0.340 \mathrm{~Hz}$ and $1.124(1 \pm 10 \%) \mathrm{Hz} \approx 1.024 \sim 1.224 \mathrm{~Hz}$, respectively.

Figure 9 shows that the responses of the girder and cable $\mathrm{C} 12$ are in the range of $0.280 \sim 0.340 \mathrm{~Hz}$ and $1.024 \sim 1.224 \mathrm{~Hz}$. The response of cable C19 under parametric and forced vibrations in the range of $0.280 \sim 0.340 \mathrm{~Hz}$ (Figure 9 (b)) is greater than the component of the response in the range of $1.024 \sim 1.224 \mathrm{~Hz}$, but is greater than that generated by forced vibration (Fig. 12 (d)).

Therefore, it can be confirmed that the second super-harmonic resonance occurs in cables C19 and C39.

The parametric vibrations in the principal unstable regions of the cables are difficult to be exhibited since, depending upon the magnitude of the exciting force, a certain amount 
of time is needed to reach the maximum amplitude in this region [4].

\section{3 Damping Effect}

In the present analysis, the damping constants $h_{c}$ of the cables are assumed to be 0.001. In fact, this bridge use high-damping rubber dampers to counteract wind-induced vibrations in the cables. Therefore, the maximum damping constant $h_{c}$ of the cables is $0.004-0.005$ [7]. The relationship between the maximum responses of the cables and the damping constant are shown in Figure 10.

For cables C12, C19, C32, and C39, the maximum amplitudes decrease as the damping constant increases. Therefore, a damping constant of $0.004-0.005$ is adequate for the cables on this bridge under wind gust of $[\notin 30 \mathrm{~m} / \mathrm{s}$. This also confirms that the damper is effective for reducing local vibrations in the cables.

\section{4 influence of Turbulent Wind Speed}

The above results are obtained for a wind velocity of $\mathrm{U}$ $=30 \mathrm{~m} / \mathrm{s}$, which is less than the design wind speed $(L=52 \mathrm{~m} / \mathrm{s})$. Figure 11 illustrates the maximum responses of the girder and cables when the wind speed is blowing at a speed of $\mathrm{U}=52 \mathrm{~m} / \mathrm{s}$. Under these conditions, local cable vibrations have the same properties. Vibrations at higher frequencies do not appear in the girder even when the wind speed is bellowing at $l \neq 52 \mathrm{~m} / \mathrm{s}$.

\section{Conclusion}

This study investigates the local vibrations in the stay cables of an actual cable-stayed bridge under wind gusts. The study includes the global vibration and local vibrations analyzed using the time-domain approach. The local cables vibrations take into account not only forced vibrations but also parametric vibrations.

The results of numerical analysis using an existing cable-stayed bridge reveal a significant difference between the forced vibration and the combined parametric and forced vibrations. Among environmental loadings and service loadings, wind loading has a much greater effect than traffic loading and leads to large-amplitude vibrations in the girder and towers. Compared to the duration of an earthquake, the total time of wind loading is considerably longer. For these reasons, local vibrations in cables are more likely to occur in windy conditions than as a result of a moving vehicle or an earthquake.
Turbulent wind produces parametric vibrations in the second unstable region of cables. Parametric vibration induces greater amplitudes than forced vibration. Second super-harmonic resonance occurs in the bottom cables of this bridge. The half of the frequencies of the bottom cables is small and prone to the first mode of global vibration, since the initial force of the bottom cables are relatively small and the frequency of the first global mode is small in a steel cable-stayed bridge.

The damping adopted to counteract wind-induced vibrations in the cables effectively reduces local nonlinear vibration in the cables.

This study does not consider the interaction between the bridge (deck/tower) and the stay cables since the laboratory did not have the FE model needed to evaluate parametric vibrations of the cables. An appropriate FE model for cables is now being formulated. The next subject for study is a gust response analysis of cable$^{-}$-stayed bridges that includes the parametric vibrations and ellipse vibrations of the stay cables.

\section{References}

1) A.M. Abdel-Ghaffar and M.A. Khalifa, Importance of cable vibration in dynamics of cable-stayed bridges, Journal of Engineering Mechanics ASCE 117, 1991, pp.2571-2589.

2) T. Yoshimura, A. Inoye, K. Kaji and M. Savage, A study on the aerodynamic stability of the Aratsu bridge, Proceedings of Canada-Japan Workshop on Bridge Aerodynamics, Nat. Res. Council of Canada, Ottawa, Canada, 1989, pp.41-50.

3) Y. Fujino and K. Kimura, Cables and cable vibration in cable-supported bridges, Proceedings of International Seminar on Cable Dynamics, Technical Committee on Cable Structures and Wind, Japan Association for Wind Engineer, Tokyo, 1997, pp.1-11.

4) Q. Wu, K. Takahashi, T. Okabayashi and S. Nakamura, Response characteristics of local vibrations in stay cables on an existing cable-stayed bridge, Journal of Sound and Vibration 261(3), 2003, pp. $403-420$.

5) M. Matsumoto, X. Chen and N. Shiraishi, Buffeting analysis of long-span bridge with aerodynamic coupling, Proceedings of National Symposium on Wind Engineering 13, 1994, pp.227-232.

6) Y. Iwatani, Simulation of multidimensional wind fluctuations having any arbitrary power spectra and cross spectra, Journal of Wind Engineering 11, 1982, 5-18.

7) Nagasaki Prefecture and Nagasaki Prefecture Road Corporation, Reports on the Ohshima Bridge Construction, 2000.

8) H.M. Irvine, Cable Structures, MIT Press, Cambridge, MA, 1981. 